\title{
Controversies regarding the role of dairy products in inflammatory bowel disease
}

\author{
SEYMOUR MISHKIN MD
}

\begin{abstract}
S MISHKIN. Controversies regarding the role of dairy products in inflammatory bowel disease. Can J Gastroenterol $1994 ; 8(3): 205-212$. Dairy products may affect inflammatory bowel disease (IBD) patients who are either lactose intolerant or who are allergic to the proteins in these foods. The actual incidence of these conditions in IBD patients is not entirely clear. Whether either of these conditions results in benign symptomatic discomfort or can actually contribute to the relapse and/or clinical activity of IBD is also unclear. Physicians differ widely in the advice they give their patients; some dogmatically advise avoidance of dairy products when the diagnosis is made while others discount their possible role in the management of IBD, On the basis of the author's and his group's experience and review of the literature, a balanced and exploratory approach by patients, physicians and dieticians is advised.
\end{abstract}

Key Words: Crohn's disease, Dairy sensitivity, Inflammatory bowel disease, Lactose intolerance, Milk allergy

\section{Controverses sur le rôle des produits laitiers dans la maladie inflammatoire de l'intestin}

RÉSUMÉ : Les produits laitiers pourraient aggraver l'état des patients atteints d'une maladie inflammatoire de l'intestin et qui ont démontré une intolérance au lactose ou une allergie aux protéines laitières. On ne connaît pas l'incidence réelle de ces troubles chez ce type de patients et on ne sait pas s'ils provoquent seulement une sensation de malaise bénin ou s'ils contribuent vraiment aux rechutes et à l'activité clinique de la maladie inflammatoire de l'intestin. Les conseils que les médecins dispensent à leurs patients à ce sujet sont très contradictoires. Certains médecins préconisent l'abandon total des produits laitiers quand le diagnostic est posé tandis que d'autres ne pensent pas que ces produits puissent entraver le traitement de la maladie inflammatoire de l'intestin. L'auteur, se basant sur son expérience et sur celle de ses collaborateurs, ainsi que sur une revue de la littérature, recommande aux patients, aux médecins et aux diététiciens d'adopter une approche exploratoire et mesurée.

Department of Medicine, McGill University and Royal Victoria Hospital, Montreal, Quebec Correspondence and reprints: Dr Seymour Mishkin, clo IBD Nutrition Review Forum, Royal Victoria Hospital, Room A3.09, 687 Pine Avenue West, Montreal, Quebec H3A IAI.

Telephone (514) 843-1578, Fax (514) 843-8182

Received for publication August 16, 1993. Accepted November 22, 1993
$\mathrm{P}$ ATIENTS SUFFERING FROM INFLAMmatory bowel disease (IBD) often face the dilemma of consuming expensive medications or considering newer experimental therapies. Medical therapy of this condition is frustrating because it is noncurative and may be associated with unpleasant side effects. Various forms of alternative medicine (ie, naturopathy, homeopathy, acupuncture) as well as many popular diet and self-help medical books often make fantastic claims of positive results in the treatment of IBD. Who is the patient to believe? What is the patient to do? In view of these considerations, we felt that the time was right for an objective review of nutritional approaches to IBD. The newly formed and still evolving IBD Nutrition Review Forum hopes to examine some of the claims made in an attempt to sort out fact from fantasy, what is worth trying although not yet proven scientifically, and what is downright misleading and based on erroneous reasoning.

This is the first of what we hope will become a series of reviews and position papers on relevant nutrition-related topics. We invite submissions and inquiries from interested physicians, dieticians, scientists and patients. Although this manuscript has been presented and circulated to IBD Nutrition Review Forum members, the conclusions are those of the author. 


\section{ULCERATIVE COLITIS}

Andresen (1) in 1925 was the first to suggest that ulcerative colitis (UC) may be due to food allergy. He later reported (2) that in $66 \%$ of his patients, one or more specific dietary items appeared to be involved in the etiology of the disease. While cow's milk was the most important (55\%), other offenders included wheat $(12 \%)$, tomatoes $(10 \%)$, oranges $(8 \%)$, potatoes $(8 \%)$ and eggs $(6 \%)$. Similar conclusions were reached by Mackie in 1938 (3) and by Rowe in 1942 (4). Truelove (5), in 1961, presented five patients with UC who had experienced definite improvement when milk was removed from their diets. Reintroduction of dairy products was associated with a reactivation of the disease within two to 42 days. Biopsy evidence documenting reactivation of disease activity was obtained in a patient previously in clinical and histological remission who began consuming a 'helping of uncooked cheese' each day for approximately 10 days. Wright and Truelove (6) estimated that a milk-free diet was beneficial in approximately $20 \%$ of patients with active 'uncomplicated' UC who were treated with a combination of oral and rectally administered steroids for two months. Twenty-four patients consumed a normal 'dummy' diet and 26 a milk-free diet for one year. Patients on the milk-free diet had fewer relapses than those on the dummy diet. The milk-free diet appeared to be more effective in first attacks than in chronic disease. In all of the studies cited above, there was no apparent correlation between circulating antibodies to cow's milk and the clinical observations.

In a search for alternative hypotheses to explain the apparent intolerance and/or allergy to cow's milk in UC, the possible role of lactose intolerance secondary to a deficiency of the disaccharidase, lactase, was entertained by Binder et al (7) who identified lactose intolerance in $49 \%$ of 39 patients using a $100 \mathrm{~g}$ lactose challenge and measurement of blood glucose levels (lactose tolerance test). A lactose-free diet benefitted $47 \%$ of UC patients including four who had a previous history of milk intolerance. The flaw in the study relates to the fact that because betagalactosidase (ie, lactaid) was not yet available commercially to break down the lactose in milk, a 'lactose-free diet' was in fact a milk-free diet.

The terms 'milk allergy' or 'hypersensitivity' are reserved for those reactions shown to be mediated by the immune system. Intolerance to dairy products should be used to describe nonimmunological adverse reactions, ie, lactose and/or fat intolerance (8). Allergic reactions to milk proteins (or rarely to contaminant antibiotics) may be immediate (within $2 \mathrm{~h}$ after ingestion) intermediate (between 2 and $24 \mathrm{~h}$ ) or delayed (longer than $24 \mathrm{~h}$ ) (9). Immunoglobulin (Ig) E-mediated milk allergies usually manifest within 30 mins but may occur within a few days. The presence of $\operatorname{IgE}$ antibodies against milk protein can be documented by prick skin tests as well as in vitro tests such as the radioallergosorbent test (RAST) and enzyme-linked immunoadsorbent assay (ELISA). Clinical features supporting the diagnosis of milk allergy include respiratory (rhinorrhea, wheeze, stridor and cough) cutaneous (urticaria, angioedema, eczema) and gastrointestinal symptoms (vomiting, cramping, distension and diarrhea). Most patients with cow's milk allergy are skin-test negative to milk extract and do not show serological evidence of IgE hypersensitivity to cow's milk. Children with this condition can develop three forms of IBD-like syndromes: milk-induced colitis, milkinduced eosinophilic enteropathy and milk-induced benign proctitis (10). A child is declared to be non-cow's milk allergic if $300 \mathrm{~mL}$ of cow's milk daily is tolerated for four weeks.

Further evidence that lactose intolerance did not account for 'milk allergy' came from the observations of Gudmand-Hoyer and Jarnum (11) who documented a $24 \%$ beneficial response to a milk-free diet in 21 patients with $\mathrm{UC}$, none of whom had lactose intolerance (according to the $100 \mathrm{~g}$ lactose tolerance testing used by Binder). The bottom line of 45 years of clinical observation (1925-70) was that at least $20 \%$ of patients with UC benefit from a milk-free diet irrespective of whether they are 'milk allergic' or lactose intolerance. The results of these studies are summarized in Table 1. Newcomer and McGill (12) who summarized the 'state of the art' in 1967 noted that four of their 24 patients $(17 \%)$ with UC were milk intolerant while only one of the four were lactose intolerant. They concluded that "from a practical standpoint, withdrawal of milk from the diets of patients who had active ulcerative colitis seems justified regardless of the history. Later, when symptoms have subsided, tolerance to lactose can be determined or milk can be added to the diet with careful observation for any change in gastrointestinal symptoms." The authors also documented that there was no significant decrease in the mucosal concentrations of lactase, sucrase and maltase activities in UC compared with healthy controls. The consensus with respect to lactase activity in UC is that a temporary reduction may occur during an actual attack but no permanent deficiency develops $(13,14)$. By studying a population with an inherently low incidence of lactose intolerance, Busk et al (15) documented that there was no evidence that active UC was associated with a higher incidence of lactose intolerance. Based on diminished lactase enzyme activity in jejunal biopsies and a flat blood glucose curve after a $100 \mathrm{~g}$ lactose challenge, lactose intolerance was documented in only $9.2 \%$ of 120 patients with UC. This prevalence was in keeping with that previously recorded in the normal Danish population.

In spite of multiple studies, there is no evidence, to date, of an increased incidence of lactose intolerance in patients with UC when ethnic heritage is taken into account. Di Palma and Narvaez (16) analyzed their hydrogen breath testing data after a lactose challenge of $50 \mathrm{~g}$ in terms of the ethnic heritage of their subjects. On the basis of ethnic heritage, subjects were assigned to three predicted prevalence categories: high prevalence (greater than 90\%) - ie, Orientals, Native Americans; moderate prevalence $(60$ to $70 \%$ ) - ie, American Blacks, Arabs, Jews, Hispanics and South Europeans (Italians and Greeks); and low preva- 
TABLE 1

Response of active ulcerative colitis to milk-free diets

\begin{tabular}{|c|c|c|c|c|c|c|c|c|c|c|}
\hline Author (reference) & Year & $\mathrm{Dx}^{*}$ & Pts & Criteria for 'food allergy' & $\% D S$ & $\%$ LI & Response & Time frame & Specific Rx for UC & Comments \\
\hline Andresen $(1,2)$ & $1925-41$ & 1 & 50 & $\begin{array}{l}\text { Food dairy }{ }^{\dagger} \\
\text { elimination diet }\end{array}$ & 55 & $?$ & $\begin{array}{l}70 \% \text { response } \\
(2 \% \text { mortallity) }\end{array}$ & Months & - & 'Allergies' not static \\
\hline Mackie (3) & 1938 & 1 & 67 & $\begin{array}{l}\text { Food dairy }{ }^{\dagger} \\
\text { elimination dlet }\end{array}$ & ? & $?$ & $?$ & Weeks & - & $\begin{array}{l}\text { 'Allergies' not static, } 70 \% \text { in } \\
\text { acute phase, } 2 \text { to } 10 \% \text { In } \\
\text { remission }\end{array}$ \\
\hline Rowe (4) & 1942 & 1 & 14 & $\begin{array}{l}\text { Food dairy }{ }^{\dagger} \text {, } \\
\text { cereal-free, frult-free } \\
\text { elimination diet }\end{array}$ & 43 & $?$ & $\begin{array}{l}71 \% \text { response } \\
\text { (50\% complete, } \\
21 \% \text { partial) }\end{array}$ & Weeks to months & Sulfonamides & $\begin{array}{l}\text { Seasonal variation in 'food } \\
\text { allergles' }\end{array}$ \\
\hline Truelove (5) & 1961 & 2 & 5 & $\begin{array}{l}\text { Improved off dairy }{ }^{\dagger} \text {, } \\
\text { relapse on dairy }\end{array}$ & 100 & $?$ & $100 \%$ response & Weeks to months & $\begin{array}{l}\text { Corticosterolds, } \\
\text { salazopyrene }\end{array}$ & Highly selected population \\
\hline Wright/Truelove (6) & 1965 & 2 & 50 & $\mathrm{None}^{\dagger}$ & $?$ & $?$ & $\begin{array}{l}20 \% \text { fewer } \\
\text { relapses on milk- } \\
\text { free diet }\end{array}$ & 1 year & Corticosteroids & $\begin{array}{l}\text { Controlled study }{ }^{\S} \text { for pts } \\
\text { willing to follow diet for one } \\
\text { year }\end{array}$ \\
\hline Binder et al (7) & 1966 & 2 & 39 & History & 49 & 13 & $47 \%$ response & Months & $\begin{array}{c}\text { Corticosteroids, } \\
\text { salazopyrene }\end{array}$ & $\begin{array}{l}\text { 'Lactose-free diet' was in } \\
\text { fact millk-free, thus, no way } \\
\text { to differentiate effects on } \\
\text { LI versus 'mllk allergy' }\end{array}$ \\
\hline $\begin{array}{l}\text { Gudmand-Hoyer/ } \\
\text { Jarnum (11) }\end{array}$ & 1970 & 2 & 21 & History & ? & 0 & $24 \%$ response & Months & $\begin{array}{c}\text { Corticosteroids, } \\
\text { salazopyrene }\end{array}$ & $\begin{array}{l}\text { Milk-free diet treats more } \\
\text { than Just LI }\end{array}$ \\
\hline
\end{tabular}

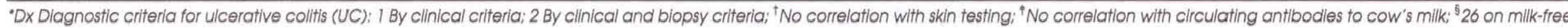

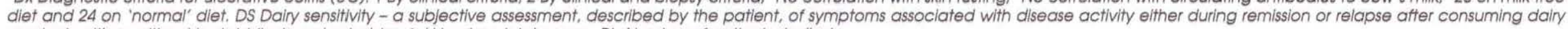
products with or without lactaid (beta galactosidase); LI Lactose intolerance; Pts Number of patients studied

\section{TABLE 2}

\section{Response of Crohn's disease to milk-free diets}

\begin{tabular}{|c|c|c|c|c|c|c|c|c|}
\hline Author (reference) & Year & Number of patients & Clinical status & $\% D S$ & $\%$ LI & Response & Time frame & Response controls \\
\hline Gudmand-Hoyer (11) & 1970 & 9 & Active & $?$ & $?$ & $33 \%$ & Months & - \\
\hline Hunter et al (13) & 1985 & 20 & Remission & $?$ & $?$ & $70 \%(n=10)$ & 6 months & $0 \%(n=10)$ \\
\hline Hunter et al (14) & 1987 & 77 & Remission & 37 & $?$ & $66 \%$ & Months to 4 years & - \\
\hline Hunter et al (15) & 1992 & 136 & Remission & $?$ & $?$ & $53 \%(n=241)$ & 1 year & $26 \%(n=38)$ \\
\hline Glaffer et al (25) & 1991 & 38 & Remission & $30^{\dagger}$ & $?$ & $31 \%(n=27)$ & 3 years & $18 \%(n=11)$ \\
\hline
\end{tabular}

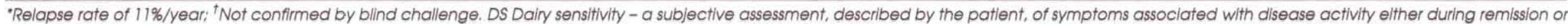

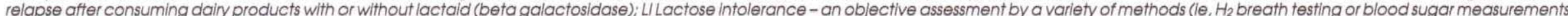

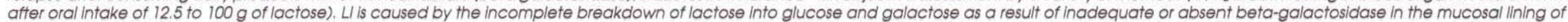

the small bowel 
136 consecutive patients with active Crohn's disease

nine hospitals

"mild $\rightarrow$ severe"

new onset $\rightarrow 10$ years duration

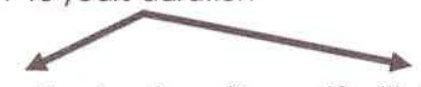

93 treated in hospital with elemental diet (no other treatment)

43 withdraw within seven days (disposition?)

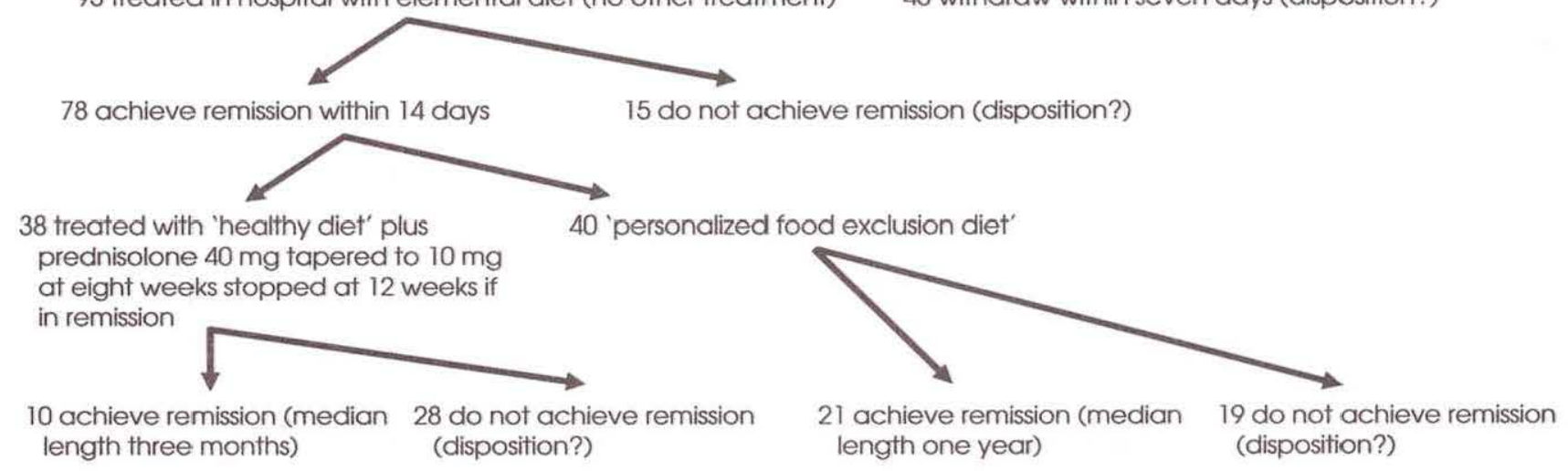

Figure 1) Schematic diagram depicting the various patient groups and the results of the pharmaceutical and nutritional managements offered to 136 consecutive patients with Crohn's disease of varying severity and duration. The raw data were obtained from reference 20 and from The Journal (Canadian Foundation for Iletis and Colitis) 1992;Sept:7

lence (10 to $15 \%)$ - ie, northern and western Europeans and Americans of similar extraction. This scheme is only applicable to the hereditary form of lactose intolerance which is not associated with any organic gastrointestinal disorder. Furthermore the author is unaware of documented activation or worsening of this disease by lactose alone. A recent study conducted in Japan documented that drinking milk seemed to be a factor in relapse in 70 patients with $\mathrm{UC}$ in remission who were followed for one year (no numbers given) (17). The authors speculate that the high incidence of lactose intolerance in Japan may account for this observation.

\section{CROHN'S DISEASE}

The largest body of work implicating dairy products in the activity of $\mathrm{CD}$ (Table 2) is based on the work of Jones and Hunter published between 1985 and 1992 (18-20). Gudman-Hoyer (11) in 1970 reported that three of nine $\mathrm{CD}$ patients, none of whom was lactose intolerant, benefitted from a milk-free diet. Except for a very interesting milksensitive nonlactose intolerant patient whose steroid refractory $\mathrm{CD}$ went into remission with the avoidance of dairy products (21), there is no documenta- tion of milk allergy or sensitivity as a factor in the activity of $\mathrm{CD}$. The efficacy of elemental diets, which are in fact milk-free, in the management of acute CD $(22,23)$ is a separate issue and will not be dealt with in this review.

The earliest study from the Cambridge group (18) reported on $20 \mathrm{pa}$ tients in whom remission had been induced with total parenteral nutrition $(n=13)$ or an elemental diet $(n=7)$. Patients were then randomized to either an unrefined carbohydrate fibre-rich diet or a diet that excluded specific foods to which a patient was intolerant. Seven of 10 patients on the exclusion diet remained in remission for six months compared with none of 10 on the other diet.

In an uncontrolled study (19), an exclusion diet allowed 51 of 77 patients to remain well on diet alone for up to 51 months, with an average annual relapse rate of less than $10 \%$. These authors introduced foods one a day in the order that allows a nutritionally adequate diet to be built up most rapidly. Three portions of a food were eaten on its test day, and if no symptoms were noted, it was subsequently eaten ad libitum. If it appeared to provoke symptoms, it was avoided and only 'safe' foods were eaten until the patient was symptom-free again, when further testing was resumed. Patients were instructed to take only elemental diet and spring water for three to four days before returning cautiously to their personal diet if they developed any symptoms.

Sixty-four of the 77 patients completed the process of 'food testing' to find a diet on which they remained well for at least three months with no other treatment. The foods most commonly associated with intolerance were wheat (28 patients, 44\%) and dairy products ( 24 patients, $37.5 \%$ ). The estimated incidence of lactose intolerance in this population is approximately $15 \%$ (personal communication).

Subjective improvement was accompanied by normalization of the erythrocyte sedimentation rate and serum orosomucoid levels and by radiological improvement in those willing to undergo a follow-up $\mathrm{x}$-ray. Jones, in a follow-up report (19), concluded that uncontrolled clinical experience with 77 patients showed that 'personalized food exclusion diets' were associated with an average annual relapse rate of only $11 \%$ for the first five years of therapy with diet alone. She suggests that 
the rate of relapse observed by the European Cooperative Crohn's Disease Study (ECCDS) (24) can be used as a control. In the European study, $90 \%$ of patients, allocated to placebo once in remission, had relapsed at the end of follow-up at two years, while approximately $60 \%$ of patients treated with steroids or steroids plus salazopyrine had suffered a relapse. Jones concluded that the avoidance of specific foods appears to be superior to the medical management of $\mathrm{CD}$ and equals the results following successful surgery, the average annual relapse rate for both being approximately $10 \%$.

Having compared the placebo management offered by both the Cambridge group (18) and the ECCDS, I question the validity of the comparisons made. In the ECCDS, follow-up occurred at three-month intervals. At each visit, results of a brief medical history, physical examination and laboratory assays of blood, serum and urine were obtained. The CD activity index was also determined. In the Cambridge study, patients were seen by a physician every month and by a dietician as often as was thought necessary to give them adequate 'guidance and encouragement' in keeping to their diets. I have often wondered about the role of frequent 'guidance and encouragement' on the clinical course of IBD. Until this matter is properly studied, I deem the placebo group chosen by Jones as inappropriate.

Riordan and Hunter (20), regarding patients with $C D$ who had achieved remission on an elemental diet, claim that 21 of 40 patients $(52.5 \%)$ on diet alone for 12 months were in remission compared with 10 of 38 patients (26.3\%) who were treated with decreasing doses of prednisone during a 12 -week period. It is noted that 43 of 136 patients $(31 \%)$ initially entering the trial abandoned the initial treatment with the elemental diet. Of the remaining 93 patients, 78 (84\%) subsequently achieved remission within 14 days and were then randomized to either corticosteroids or diet (Figure 1). The authors conclude that an "elemental diet followed by identification of food intolerance presents an effective strategy for long term management of acute CD". I would like to point out that in the September 1992 issue of The Journal (Canadian Foundation for Iletis and Colitis), one page was devoted to this rather complex study. No comments or figures were appended to discuss or interpret the results. (The work has recently been published again [25]). No other centre has yet succeeded in reproducing the findings claimed by the Cambridge group.

In 1991, Giaffer et al (26) reported somewhat different results in $27 \mathrm{pa}$ tients with $\mathrm{CD}$ who attained clinical remission after four weeks of enteral feeding. Five of the 14 patients who completed testing for specific food intolerances could not identify any trigger foods; the remaining nine were maintained on exclusion diets, three of whom relapsed early. In this study, over $30 \%$ of patients tested for food intolerance did not identify specific trigger foods; this contrasts the claim by the Cambridge group that over $90 \%$ of CD patients could identify specific foods to which they were intolerant (18). Four of these nine patients agreed to undertake double-blind re-challenge tests, all of which were negative. The authors commented that the negative results of the blind challenges may indicate either that food aversion is responsible or that food-related reactions are delayed for over $24 \mathrm{~h}$. In spite of this, six of nine patients $(66 \%)$ on exclusion diets and two of $11(18 \%)$ on a normal diet remained in remission. The authors concluded that while not statistically significant, there was a trend in favour of exclusion diet. The authors also observed that disease location was the single most important determinant of the subsequent course after treatment with elemental diet. Of the patients with large bowel involvement, $80 \%$ relapsed early.

In Levi's review (27) of diet in CD management, he expresses his scepticism regarding the work of Hunter and co-workers. "Aided by the media ... these studies have stimulated enormous public interest, so that now gastroenterologists are constantly asked by their patients whether they should go onto an elimination diet and whether a spe- cific food intolerance is the cause of their disease ..." Levi notes, and concludes that "ultimately double blind challenges as well as controlled trials are required. At present, the place of exclusion diets in the management of CD is not known."

Ginsberg and Albert (21) report on a patient whose longstanding steroiddependent $\mathrm{CD}$ went into remission after 10 weeks of consuming only Ensure Plus (Ross Laboratories) and tap water. During this time the patient became completely asymptomatic and his prednisone was tapered over an eight-week period and then discontinued for the first time in three years. Following this, his diet was gradually liberalized to include 'safe' foods (no adverse effect consuming this food along with Ensure Plus three times a day for three days; if symptoms developed the patient was instructed to eat only Ensure Plus and the previously determined 'safe' foods until symptoms subsided). Lactaidtreated milk gave a violent reaction after six glasses on the first day. A relapse of Crohn's-related symptoms lasting one week ensued and gradually disappeared one week later without the use of prednisone. Following remission for one year, a repeat small bowel series showed marked improvement. A $25 \mathrm{~g}$ lactose challenge (equivalent to the lactose contained in two glasses of milk) produced no symptoms while a double-blind milk challenge using $5 \mathrm{~mL}$ of whole milk resulted in a recurrence of severe cramping and diarrhea. This attack was aborted by taking 20 mg of prednisone for three days. "Eighteen months after total clinical and laboratory remission had been induced by Ensure Plus, the patient continued on a strict milk-free diet and remained well without requiring any medication, and with all laboratory studies in the normal range. At that point, the patient voluntarily underwent a rechallenge with whole milk, lactose and lactoglobulin, all of which now failed to elicit any symptoms. He has since returned to his strict milk-free diet and remains in total remission." Clearly in this case of $\mathrm{CD}$, one can conclude that a hypersensitivity to dairy products, but not to lactose, was operative in the ac- 
tivation of the disease process. The authors make the interesting comment that "although we have been able to induce remission in $40 \%$ of our steroiddependent $\mathrm{CD}$ patients with Ensure Plus (28), in no other patient have we yet been able to isolate a specific food that consistently reproduced symptoms". I was disappointed, when I reviewed the abstract cited, to learn that these conclusions were based on experience with only seven $\mathrm{CD}$ patients. The question remains whether the incidence of sensitivity to dairy products really exists in $37.5 \%$ of patients with $\mathrm{CD}$ - as suggested by the work of Jones and Hunter - or is a rare occurrence as described above in a single patient. The discussion of exclusion diets in this paper is primarily related to the withdrawal of dairy products and is not intended to deal with the issue of exclusion diets in general. Russell (29), in a recent review, comes to the following conclusion: "there is a suspicion that some specific improvement in activity of $\mathrm{CD}$ can be achieved by dietary and nutritional manipulation. However, there is a cogent need for well-planned prospective studies in much larger numbers of patients for longer periods of time, in which good scientific methods of assessing improvement in disease activity are used in conjunction with good nutritional data...."

\section{LACTOSE INTOLERANCE}

It has been said that the incidence of lactose intolerance or malabsorption seems to be increased in adult patients with $\mathrm{CD}$, especially in patients who have undergone intestinal resection (30). In CD patients without resection, $33 \%$ - compared with $16 \%$ of normal controls - met the criteria of lactose intolerance during hydrogen breath testing after a lactose challenge of $12.5 \mathrm{~g}$ (equivalent to the lactose content in one cup of milk). In patients who underwent intestinal resection, the incidence of lactose intolerance was $58 \%$. In the entire group of $\mathrm{CD}$ patients studied (all Caucasian, nonJewish, originating from northern and central Italy), $48 \%$ were lactose malabsorbers after a lactose challenge of 12.5 $\mathrm{g}$, while only $8 \%$ experienced immedi- ate symptoms of intolerance after the ingestion of one cup of milk $(250 \mathrm{~mL}$ containing $12.4 \mathrm{~g}$ of lactose). Lactose loads used ranged between 12.5 and $100 \mathrm{~g}$. Clearly $100 \mathrm{~g}$, which corresponds to the lactose contents of $2 \mathrm{~L}$ of milk, is unrealistic in terms of normal intake, but $12.5 \mathrm{~g}$, which corresponds to one glass of milk, is less than taken in normally and picks up too few patients with lactose intolerance. Less comprehensive analyses were carried out after lactose challenges of 25 and $50 \mathrm{~g}$. The effect of dose on the apparent incidence of lactose intolerance was studied by Pironi et al (30). In 67 healthy Italian subjects after the ingestion of $12.5,25$ and $50 \mathrm{~g}$ lactose, the cumulative percentages of malabsorbers rose from 16 to 31 to $65 \%$. It is the bias of the author that a $25 \mathrm{~g}$ challenge representing the lactose content of two cups of milk $(500 \mathrm{~mL})$ is realistic. In addition, we will advise patients to use lactaid only if symptoms were experienced during or immediately after the test.

In some centres lactose intolerance testing is carried out by measuring the change in plasma glucose concentration following an oral challenge of lactose. To achieve a consistent separation of absorbers and nonabsorbers via changes in plasma glucose (at least 20 $\mathrm{mg} / \mathrm{mL}$ ), relatively large doses (ie, $50 \mathrm{~g}$ ) must be used. Breath hydrogen testing, a noninvasive method that can use more physiological doses, has displaced blood testing for glucose in most labs. Hydrogen, which is not normally manufactured by humans, is liberated during the colonic fermentation of unabsorbed carbohydrate. False-negative results may occur in a minority of subjects who have colonic flora that does not produce appreciable amounts of hydrogen during fermentation (31). For the same reason, hydrogen breath testing should not be undertaken within two weeks of taking antibiotics.

False-positive results can be prevented by avoiding the intake of complex carbohydrates in various beans and vegetables $24 \mathrm{~h}$ before testing. It is claimed that smoking, sleeping or eating shortly before or during the test can give a false-positive test (32). Bacterial overgrowth, in which case colonic flora is found in the small bowel, will elevate fasting breath hydrogen.

In a study of children (given $12 \mathrm{~g}$ lactose) and adolescents (given $25 \mathrm{~g}$ lactose) by Kirschner et al (33) a higher than expected incidence of lactose intolerance was noted in 'Caucasian gentiles' with $\mathrm{CD}$ but not in a group with UC matched for ethnic heritage. This difference in lactose intolerance was not found when Caucasian Jews with $\mathrm{CD}$ were compared with a group matched for ethnic heritage with UC, with the exception of patients with diffuse small bowel disease. The location of intestinal involvement with $\mathrm{CD}$ and the severity of clinical symptoms did not affect the incidence of lactose malabsorption. In a recent prospective survey of 222 adult patients with IBD (118 with UC and 104 with CD) (34), a history of sensitivity to dairy products (a subjective assessment, described by the patient, of symptoms associated with disease activity either during remission or relapse after consuming dairy products with or without lactaid [beta-galactosidase]) was obtained in 14.4 and $11.5 \%$ of all patients with UC and $\mathrm{CD}$, respectively. The highest incidence of dairy sensitivity, $16.9 \%$, was recorded in the group of patients with UC who had a moderate risk (60 to $70 \%$ ) according to their ethnic heritage of being lactose intolerant. The incidence of dairy sensitivity in UC patients with a low risk of lactose intolerance ( 10 to $15 \%$ ) was $12.9 \%$. The corresponding incidences of dairy sensitivity in $\mathrm{CD}$ patients at moderate and low risk for lactose intolerance were 12.9 and $9.1 \%$, respectively. Thus, there appears to be an excess of dairy sensitivity in lactose intolerant patients. This may be due to the difficulty in differentiating between the symptoms resulting from dairy sensitivity or lactose intolerance. The incidence of lactose intolerance did not appear to be greater in dairy sensitivity patients compared with the entire IBD population studied. The corresponding figures for lactose intolerance in patients with $U C$ and $C D$ were 16.0 and $10.6 \%$, respectively, after a lactose challenge of $25 \mathrm{~g}$ (equivalent to the lactose content of two cups of milk). In this study, a 
history of drug allergy was not helpful in identifying patients who were dairy sensitive.

The amount of lactose administered for hydrogen breath testing is arbitrary, ranging from 12 to $50 \mathrm{~g}$ (equivalent to the lactose content in one to four cups of milk). The apparent incidence of lactose intolerance, as defined by a rise in breath hydrogen of at least $200 \mathrm{ppm}$, will increase as the dose of lactose is increased. In addition, lactose intolerance patients will exhibit a wide range of sensitivity to a given amount of lactose as indicated by the recorded rise in breath hydrogen, as well as the severity of symptoms experienced. I recommend that a $25 \mathrm{~g}$ lactose challenge be used as the standard test dose. I have been impressed by the symptomatic improvement in lactose intolerance patients and high degree of compliance with the appropriate diet and enzyme replacement (beta-galactosidase). Lactose intolerance patients who are restricting their intake of dairy products should receive appropriate calcium supplementation. In a study of $65 \mathrm{pa}-$ tients with lactose and other intolerances who completed a questionnaire (35), 75\% categorized their lactose intolerance as a 'major problem'. In excess of $60 \%$ found that their symptoms improved by more than $50 \%$ with appropriate measures, which were adhered to in more than $90 \%$ of cases. Ninety-three per cent of those surveyed felt that breath testing and dietary guidance had been worthwhile.

The figures for dairy sensitivity in $\mathrm{CD}$ patients in this study are similar to the $8 \%$ observed in Italian patients with $C D$ by Pironi et al (30), but are significantly lower than the $37.5 \%$ incidence quoted by Jones et al (18). The incidences of dairy sensitivity in 14.4 to $16.0 \%$ of patients with UC are reminiscent of the estimates of approximately $20 \%$ made by Wright and Truelove (6). The incidence of lactose intolerance in patients expected to have a moderate incidence ( 60 to $70 \%$ ) based on ethnic heritage was not different for patients with CD or UC ( 66.6 and $61.0 \%$, respectively). In contrast, in $\mathrm{CD}$ patients with a low predicted incidence, ie, 'low risk ethnic heritage' (10 to $15 \%$ ), the docu-

TABLE 3

The bottom line regarding milk-free diets in inflammatory bowel disease (1925-93)

Ulcerative colitis $\longrightarrow$ Active $\geq 20 \%$ benefit"
Crohn's disease $\longrightarrow$ Active - probably helpful
"No scientific explanation (no correlation with immunological testing or lactose intolerance)

mentation of lactose intolerance in $33.3 \%$ was significantly greater $(\mathrm{P}<0.065)$ than the $14.3 \%$ incidence noted in the comparable group of UC patients. The unique clinical characteristics of these low risk ethnic heritage $C D$ patients with the higher than expected incidence of lactose intolerance compared with the remaining groups were: a preponderance of females $(88.9 \%$ versus less than $50 \%$ ); and history of bowel resection in $77.7 \%$ (compared with $42 \%$ or less). These findings agree with the observations of Kirschner et al in 'Caucasian gentile' children and adolescents with CD (33).

\section{CONCLUSIONS}

The incidence of dairy sensitivity in IBD patients is probably in the range of 10 to $20 \%$. The incidence of lactose intolerance is no greater than expected by ethnic heritage except for a possible increased incidence in a subgroup of 'low risk' or 'Caucasian gentile' patients with $\mathrm{CD}$, most of whom are females who have undergone surgery for their disease. Additional studies are needed to validate the above-mentioned conclusions. Reactions to dairy products may occur as a result of lactose intolerance or a reaction to the proteins and other components (dairy sensitivity). It is also important to realize that these reactions, especially those unrelated to lactose intolerance, may occur after many weeks of repeated consumption rather than immediately after intake. To date, skin testing or measurement of circulating antibodies to cow's milk have not been helpful in the prediction of dairy sensitivity. With respect to UC in the active phase, it appears that at least $20 \%$ of patients will benefit from a milk-free diet. There are no published data on the response of $\mathrm{UC}$ in remission. $\mathrm{CD}$, on the other hand, appears to respond in both the active and quiescent phases. Elemental diets that are also milk-free will uniformly benefit these patients in the acute phase. Once in remission, apparently $30 \%$ or more of CD patients manage to stay in remission with avoidance of dairy products and other 'offending' foodstuffs. The scientific basis for these observations (Table 3 ) is lacking and except for one study (26), blinded food challenges have not been carried out. We (the author and the IBD Nutrition Review Forum) recommend that this information be taken into account in the dietary management of patients with IBD, especially when they are not responding to conventional therapy. We urge physicians and dieticians to offer their patients adequate information and guidelines to enable them to determine whether dairy products are responsible for some of their gastrointestinal symptoms and whether further investigation is warranted. It is my bias that lactose breath testing should be offered to most patients with IBD. We feel that the information provided by this noninvasive test is important in the nutritional management of IBD patients. Elimination or exclusion diets involving milk withdrawal where indicated are best worked out by specially trained dieticians working with the treating physicians. Dairy products constitute an important source of calcium and other nutrients and their intake should not be discontinued arbitrarily. If there is a valid reason to curtail the intake of cairy products, provisions should be 
made to obtain calcium and other nutrients from alternative sources.

We advise that lactose breath testing to confirm lactose intolerance be carried out before beta-galactosidase preparations are used to reduce the lactose content of dairy products. We also recommend that organizations that publish and circulate the results of nutritional studies to their members should ensure that this material has been carefully screened, properly 'digested' and evaluated for their readers who are eagerly searching for new breakthroughs in the management of their IBD.

ACKNOWLEDGEMENTS: We appreciate the feedback provided by the IBD Nutrition Forum Members. We thank Domenica Farinacci-Cami for her secretarial services. The costs involved in the preparation of this manuscript were defrayed by contributions from the corporate sponsors of the IBD Nutrition Review Forum (Clintec Nutrition, Janssen Pharmaceutica Inc, McNeil Consumer Products, Organon, Procter and Gamble, and Sandoz Nutrition).

\section{REFERENCES}

1. Andresen AFR. Gastrointestinal manifestations of food allergy. Med J Rec 1925;122:171-5.

2. Andresen AFR. Ulcerative colitis - an allergic phenomenon. Am J Dig Dis 1942;9:91-7.

3. Mackie TT. The medical management of chronic ulcerative colitis. JAMA 1938;iii:2071-6.

4. Rowe AH. Chronic ulcerative colitis allergy in its etiology. Ann Intern Med 1942;17:83-100.

5. Truelove SC. Ulcerative colitis provoked by milk. Br Med J 1961;1:154-60.

6. Wright R, Truelove SC. A controlled therapeutic trial of various diets in ulcerative colitis. Br Med J 1965;22:138-41.

7. Binder HJ, Gryboski JD, Thayer WR $\mathrm{Jr}$, Spiro HM. Intolerance to milk in ulcerative colitis: A preliminary report. Am J Dig Dis 1966;11:858-64.

8. Shanahan F, Targan SR. Gastrointestinal manifestations of immunologic disorders. In: Yamada T, ed. Textbook of Gastroenterology. New York: JB Lippincott, 1991:2157-71.

9. Thomson DMP. Food allergies: workup for detecting the cause. Can J CME 1989;May:25-35.

10. Hill DJ, Hosking CS. Clinical management: food allergy in pediatric clinical practice. Semin Pediatr Gastroenterol Nutr 1992;3:3-8.

11. Gudmand-Hoyer E, Jarnum S. Incidence and clinical significance of lactose malabsorption in ulcerative colitis and Crohn's disease. Gut 1970;11:338-43.

12. Newcomer AD, McGill DB. Incidence of lactase deficiency in ulcerative colitis. Gastroenterology 1967;53:890-3.

13. Pena AS, Truelove SC. Hypolactasia and ulcerative colitis. Gastroenterology 1973;64:400-4.

14. Gudmand-Hoyer E, Binder V, Soltoft $J$. The small intestinal disaccharidase activity in ulcerative colitis. Scand J Gastroenterol 1975;10:209-12.

15. Busk HE, Dahlerup B, Lystzen T, Binder V, Gudmand-Hoyer E. The incidence lactose malabsorption in ulcerative collitis. Scand J Gastroenterol 1975;10:263-5.

16. Di Palma JA, Narvaez RM. Prediction of lactose malabsorption in referral patients. Dig Dis Sci 1988;33:303-7.

17. Oshitani N, Kitano A, Nakamur S, Masumoto T, Kobayashi K. Factors in relapse of ulcerative colitis. Gastroenterology 1992;102:A676.

18. Jones VA, Workman E, Freeman AH, Dickinson RJ, Wilson AJ, Hunter JO. Crohn's disease: maintenance of remission by diet. Lancet 1985;22:177-80.

19. Jones VA. Comparison of total parenteral nutrition and elemental diet in induction of remission of Crohn's disease. Dig Dis Sci 1987;32:12(Suppl)1005-75

20. Riordan AM, Hunter JO. Multicenter controlled trial of diet in the treatment of active Crohn's disease. Gastroenterology 1992;102:A685.

21. Ginsburg AL, Albert MB. Treatment of patient with severe steroid-dependent Crohn's disease with nonelemental formula diet. Dig Dis Sci 1989;34:1624-8.

22. Seidman EG. Nutritional management of inflammatory bowel disease.
Gastroenterol Clin North Am 1989;17:129-55.

23. Greenberg GR. Nutritional management of inflammatory bowel disease. Semin Gastroenterol Dis 1993;4:69-86.

24. Malchow H, Ewek JW, Brandes JW, et al. European Cooperative Crohn's Disease Study (ECCDs): Results of drug treatment. Gastroenterology 1984;86:249-66.

25. Riordan AM, Hunter JO, Cowan RE, et al. Treatment of active Crohn's disease by exclusion diet: East Anglian Multicentre Controlled Trial. Lancet 1993;342:1131-4.

26. Giaffer MH, Cann P, Holdsworth CD. Long-term effects of elemental and exclusion diets for Crohn's Disease. Aliment Pharmacol Ther 1991;5:115-25.

27. Levi AJ. Diet in the management of Crohn's disease. Gut 1985;26:985-8.

28. Ginsburg AL, Albert MB. Induction of remission in Crohn's disease with an ensure diet: Identification and exclusion of dietary substances which exacerbate disease. Gastroenterology 1988;94:A147.

29. Russell RI. Nutrition and inflammatory bowel disease. Curr Opin Gastroenterol 1992;8:688-93.

30. Pironi L, Callegari C, Cornia GL, Lami F, Migholi M, Barbara L. Lactose malabsorption in adult patients with Crohn's disease. Am J Gastroenterol 1988;83:1267-71.

31. Lloyd ML, Olsen WA. Specific mucosal protein deficiency states. In: Yamada T, ed. Textbook of Gastroenterology. New York: JB Lippincott, 1991:1521-30.

32. Solomons NW. Evaluation of carbohydrate absorption: the hydrogen breath test in clinical practice. Clin Nutr J 1984;3:71.

33. Kirschner BS, De Favaro MV, Jensen W. Lactose malabsorption in children and adolescents. Gastroenterology 1981;81:829-32.

34. Mishkin B, Yalovsky M, Mishkin S. Incidence of lactose intolerance and/or sensitivity to dairy products in patients with IBD. Gastroenterology 1993;104:A1052.

35. Mishkin SR, Sablauskas L, Mishkin S. Fructose and/or sorbitol intolerance in a sub-group of lactose intolerant patients. Gastroenterology 1992;102:A226. 


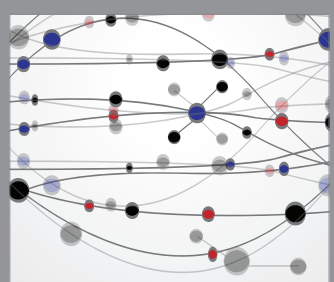

The Scientific World Journal
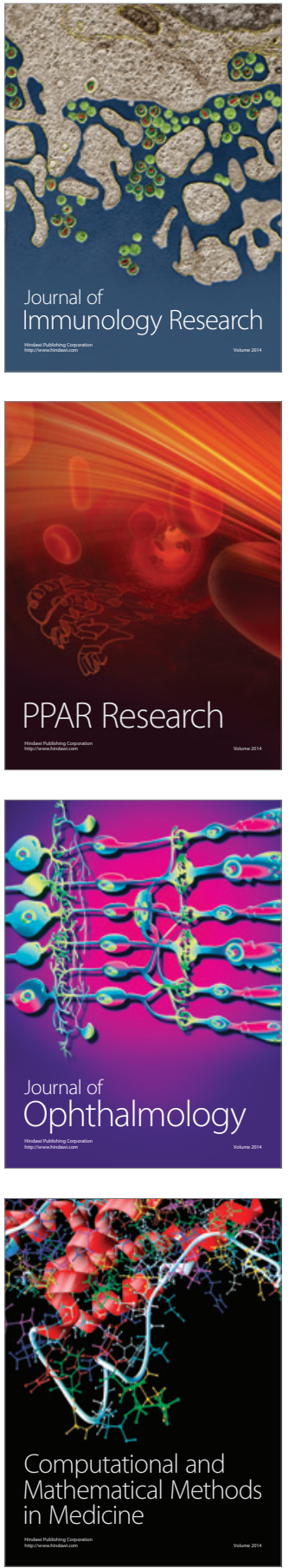

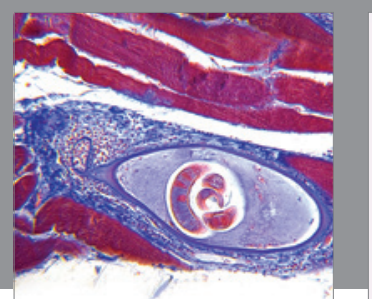

Gastroenterology Research and Practice

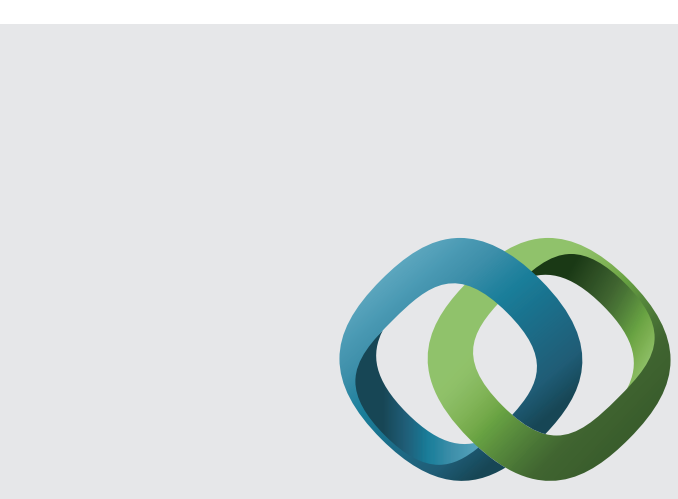

\section{Hindawi}

Submit your manuscripts at

http://www.hindawi.com
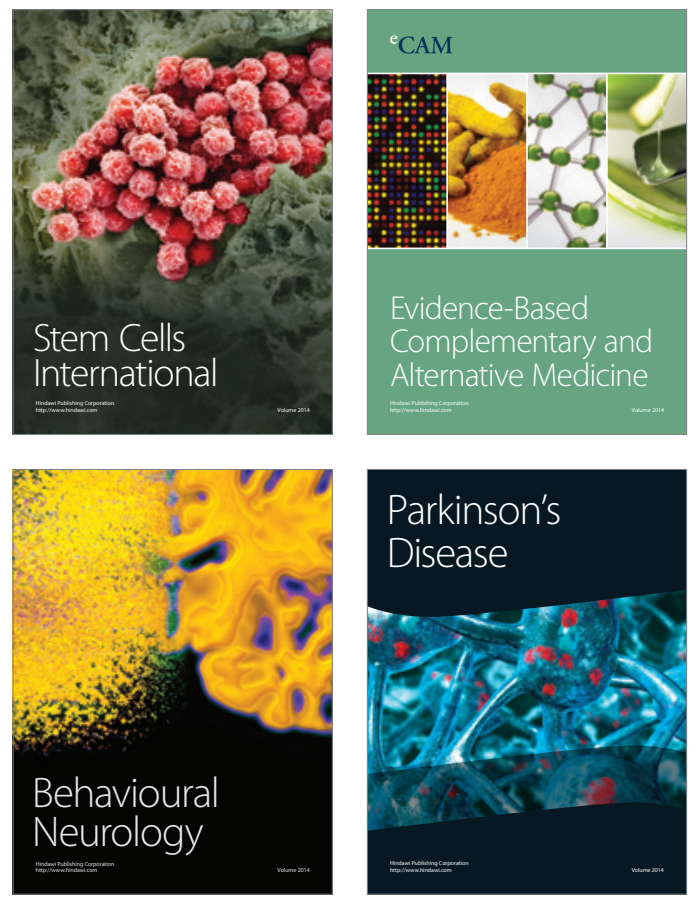
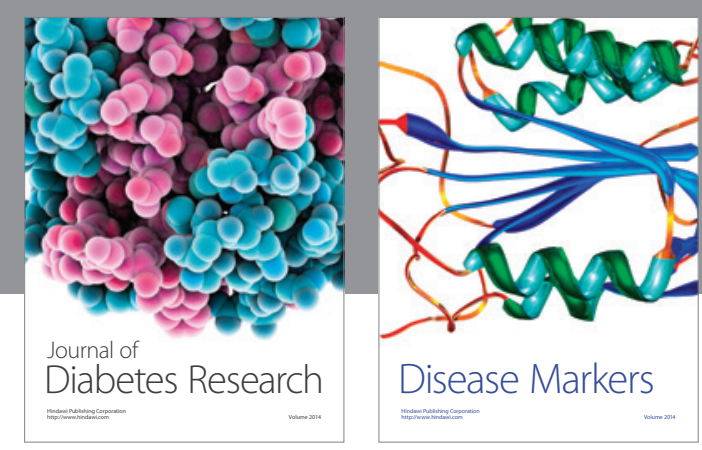

Disease Markers
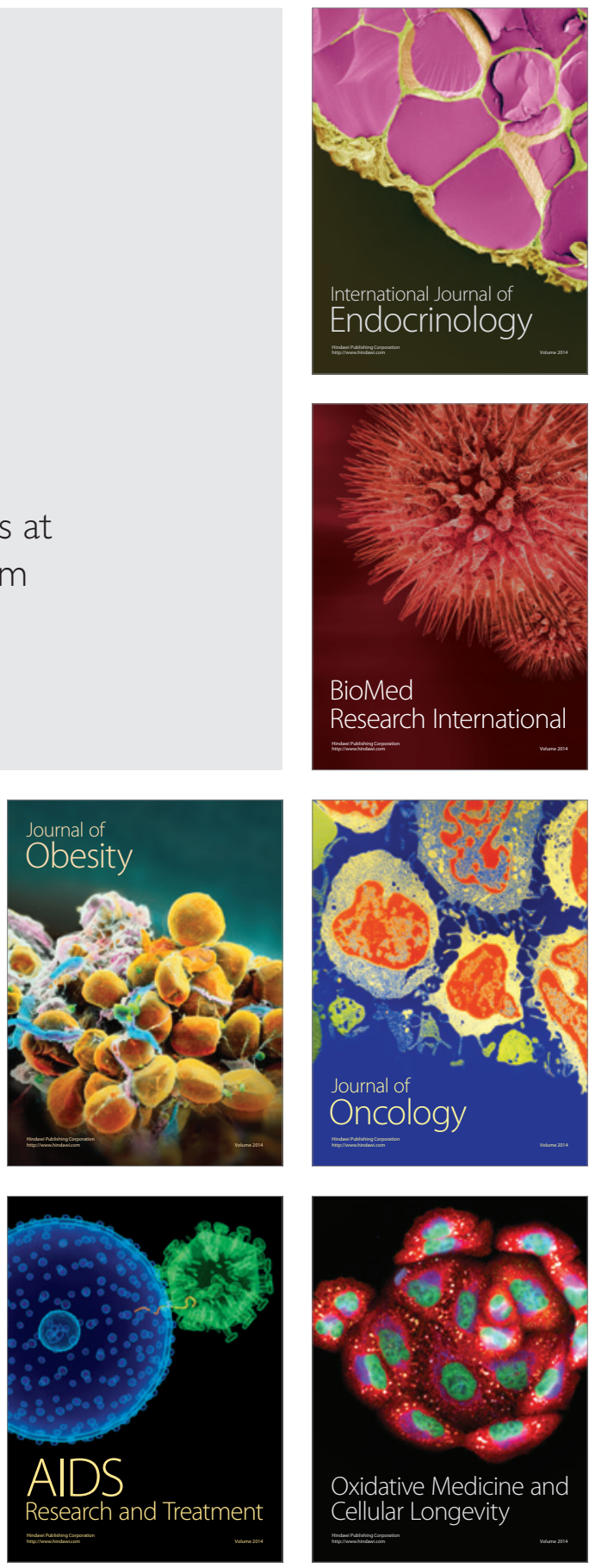